\title{
Fetal Male Sex Ratio
}

National Cancer Institute

\section{Source}

National Cancer Institute. Fetal Male Sex Ratio. NCI Thesaurus. Code C124625.

The determination of the ratio of live male fetuses compared to the total number of live fetuses present in the uterus. The measurement may be expressed as a fraction or percentage. 